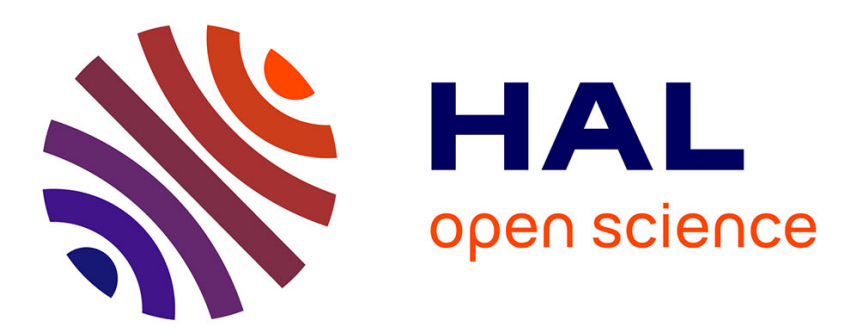

\title{
Do two heads search better than one? Effects of student collaboration on Web search behavior and search outcomes
}

Ard Lazonder

\section{- To cite this version:}

Ard Lazonder. Do two heads search better than one? Effects of student collaboration on Web search behavior and search outcomes. British Journal of Educational Technology, 2005, 36(3), pp.465-475. 10.1111/j.1467-8535.2005.00478.x . hal-00190683

\section{HAL Id: hal-00190683}

\section{https://telearn.archives-ouvertes.fr/hal-00190683}

Submitted on 23 Nov 2007

HAL is a multi-disciplinary open access archive for the deposit and dissemination of scientific research documents, whether they are published or not. The documents may come from teaching and research institutions in France or abroad, or from public or private research centers.
L'archive ouverte pluridisciplinaire HAL, est destinée au dépôt et à la diffusion de documents scientifiques de niveau recherche, publiés ou non, émanant des établissements d'enseignement et de recherche français ou étrangers, des laboratoires publics ou privés. 
Author Posting (C) Blackwell Publishing Ltd. 2005. This is the author's version of the work. It is posted here by permission of Blackwell Publishing Ltd. for personal use, not for redistribution. The definitive version was published in the British Journal of Educational Technology, 2005, 36(3), 465-475. http://dx.doi.org/10.1111/j.1467-8535.2005.00478.x

Do two heads search better than one?

Effects of student collaboration on Web search behavior and search outcomes

Ard W. Lazonder

University of Twente

Department of Instructional Technology

Contact details

Ard W. Lazonder

University of Twente

Behavioral Sciences

Instructional Technology

P.O. Box 217

7500 AE Enschede

The Netherlands

Fax: $\quad+31534892849$

Email: a.w.lazonder@utwente.nl 


\section{About the author}

Ard Lazonder is assistant professor of instructional technology at the University of Twente. He teaches courses in instructional design theories, constructivism and situated cognition. His current research interests include collaborative learning, self-regulation, inquiry learning, and information literacy. Address for correspondence: Ard Lazonder, University of Twente, Behavioral Sciences, Department of Instructional Technology, P.O. Box 217, 7500 AE Enschede, The Netherlands. Email: a.w.lazonder@utwente.nl 


\begin{abstract}
This study compared Pairs of students with Single students in Web search tasks. The underlying hypothesis was that peer-to-peer collaboration encourages students to articulate their thoughts, which in turn has a facilitative effect on the regulation of the search process as well as search outcomes. Both hypotheses were supported by the results. Pairs located the target information more often and in less time than Singles did. Pairs also employed a richer repertoire of search strategies and were more proficient in monitoring and evaluating their search behavior. Implications of these findings for practice and further research are discussed.
\end{abstract}




\section{Introduction}

About thirty years ago, information seeking was a specialism and librarians could call themselves information specialists for a reason. People in need of specific information generally consulted a librarian who had access to various information retrieval systems and was able to reveal its contents by developing sophisticated queries. The librarian would sit down with the information seeker to identify his/her information needs. Taylor (1968) classified this pre-search interview as a negotiation process in which the information specialist works with the inquirer back to his/her information needs and then translates these needs into a useful search strategy.

Nowadays most public and research library catalogues are available online, and the Internet hosts tons of information that is readily accessible to the general public. Internet technology has also found its way into schools where, among other things, the Web is being used as an arena for students to obtain information. Asking students to collect their own learning materials is consistent with contemporary notions of learning that advocate knowledge building through constructive, self-directed activities. The Web is therefore considered a potentially powerful means to mediate this new form of learning.

The advantages of online public access notwithstanding, most students are unlikely to locate information efficiently and effectively. One reason is that the Web suffers from a lack of indexing conventions. Controlled vocabularies, thesaurus classifications, and human indexing are uncommon for Web search engines. More importantly, the Web opens up so much information that designated skills to manage the information-flow are called for. Students generally lack these self-regulatory skills, which caused about half of the high school freshmen from various European countries to consider themselves incapable of searching the Web efficiently and effectively (Pelgrum, 1999; Ten Brummelhuis and Slotman, 2000). In-depth studies by Branch (2001) and Lazonder (2000) showed that teenagers are largely unable to select appropriate search strategies (planning), check their progress (monitoring) and assess the relevance of search outcomes (evaluating).

Improving searchers' abilities to self-regulate seems called for, especially because such regulatory skills are the key to successful Web searching. Yet there is little research on effective Websearching instruction. Colaric (2003) examined three instructional treatments to aid searchers in 
developing queries (ie, planning). The results were equivocal. Undergraduate students receiving worked examples yielded superior syntactic knowledge than students in the two conceptual model conditions. That is, students in the worked-example condition were more proficient in structuring a search query using terminology a search engine can interpret correctly. In contrast, conceptual model instruction was the most effective method for increasing the students' declarative understanding of how a search engine works.

Lazonder (2001) compared the instructional efficacy of two versions of self-regulatory skill instruction to a control group. His instruction was more comprehensive than Colaric's in that it taught students to plan, monitor, and evaluate a search. Results indicated that students from both selfregulatory skill groups needed about $25 \%$ more practice time than students in the control group (who were merely taught procedural skills to operate the search engine). However, self-regulatory skill instruction did not enhance search performance on test tasks. A possible explanation for this finding is that students had developed the self-regulatory skills during practice, but failed to recognize when the acquired skills should be applied on the test tasks.

The work reported here explored whether collaboration might help overcome this inert knowledge problem. The basic assumption is that experienced Web users have at least some understanding of the self-regulatory skills entailed in efficient Web searching. The presence of an equally knowledgeable peer might encourage these users to articulate their thoughts. Such verbalizations might have a positive impact on problem solving by supporting a variety of selfregulating functions (Teasley, 1995). That is, peer interaction is assumed to incite users to negotiate the suitability of search strategies and the relevance of search outcomes. Another alleged advantage of collaborative information seeking is the opportunity for users to critically observe and monitor each other's actions, which may facilitate early detection and correction of errors. Additionally, higher levels of self-regulation are assumed to be associated with better search outcomes.

Research on collaborative Web searching has recently begun to emerge. Some studies have focused on peripheral issues such as the roles individuals can adopt in collaborative information seeking (Prekop, 2002), attitude changes in intergenerational collaboration (Caskey, 2003), and gender differences in group-based information seeking (Large et al, 2002). Another line of research is 
directed towards designing interfaces and support tools to foster collaborative information seeking activities (Chau et al, 2003; Druin et al, 2003; Twidale and Nichols, 1998). Yet none of these studies report how groups of users (as opposed to individuals) organize and perform their search process, nor do they provide empirical evidence on the alleged advantages of collaborative Web searching.

Evidence on the effects of collaboration on task outcomes can be gleaned from research in other domains. Collaboration has been used successfully to promote learning across a range of curriculum areas including mathematics, science, reading and language arts. Its benefits appear to be relatively independent of group size, student age and ability. The magnitude of these effects was shown in meta-analytical studies comparing collaborative learning with whole-class instruction or individual learning (eg, Cohen, 1994; Lou et al, 2001). These studies report substantial facilitative effects of collaborative learning on both group task performance and achievement on individual posttests. Zimbardo et al (2003) further demonstrated that these findings extend to collaborative test taking. Students who prepared for a test individually performed significantly better when they took that test with a fellow student than on their own. This result is relevant to Web searching as teachers generally require students to utilize existing search expertise to find information on the Web. Practical constraints such as the availability of computers further necessitate teachers to let students perform these searches collaboratively.

Very few studies have investigated whether collaboration promotes self-regulation. To illustrate, in Lou et al's (2001) meta-analysis on the effects of small-group learning with technology, only 3 of the 122 studies addressed the use of self-regulating strategies. Although the results indicated that collaboration yielded higher frequency of using appropriate strategies, the nature of these strategies remains unknown. Fleming and Alexander (2001) give a more detailed account of the benefits of collaboration. They studied fourth-graders' strategy use during memory tasks and found that triads used more sophisticated strategies and were more aware of the usefulness of these strategies than did children who worked individually. Despite these favorable results, several properties of this study constrain its generalization. These include the nature of the target audience, the experimental task and the use of question prompts to promote children's' understanding and application of 
appropriate strategies. Consequently, there is no guarantee from Fleming and Alexander's study that collaboration will foster adolescents' self-regulation during Web searching.

Research supports the assumption that self-regulation improves academic achievement. Schauble et al (1991) found that higher levels of planning lead to higher achievement. Schraw (1994) reported similar effects for monitoring and evaluating. Other studies have found that self-regulation is a relatively general process that operates in the same fashion across different domains (eg, Veenman et $a l, 1997)$. Together these findings substantiate that planning, monitoring and evaluating can increase achievement on Web search tasks. However, as these studies were conducted on individual students, further research is needed to show whether their findings generalize to collaborative Web searching.

In summary, the cited studies strongly suggest that both collaboration and self-regulation improve search outcomes. While it seems plausible that the benefits of collaboration are at least in part attributable to higher levels of self-regulation, there is insufficient evidence to substantiate this claim. The present study therefore explored whether collaboration stimulates self-regulatory activities in students searching for information on the Web. It sought to answer this question by comparing pairs of students with individual students in Web search tasks. Pairs were expected to perform these tasks faster and better than single students. Pairs were also expected to show relatively higher proportions of self-regulatory activities such as planning, monitoring, and evaluating.

\section{Method}

\section{Participants}

Participants were first-year students in social sciences from a Dutch university. There were 9 men and 16 women with a mean age of 20 years $(\mathrm{SD}=1.99)$. Students could participate in the study as part of a self-chosen dyad or on an individual basis, leading to 9 Pairs and 7 Singles. Six of these Pairs were same-gender couples. Preliminary checks revealed no within-pair differences based on computer experience and Web searching experience.

\section{Materials}


A background questionnaire determined the participants' gender, age, computer experience and hours per week spent searching the Web. The Motivated Strategies for Learning Questionnaire (MSLQ) assessed different facets of self-regulation, including self-efficacy, task value, test anxiety, cognitive strategies, and metacognitive strategies (Pintrich et al, 1993). The MSLQ was preferred over other self-report questionnaires because its 53 items can be tailored to specific situations or content areas. Participants judged each item on a Likert scale that ranged from 1 (not at all true of me) to 7 (very true of me). All scales demonstrated satisfactory psychometric properties with internal consistency reliabilities in excess of 0.79 .

Six fact-finding search tasks assessed the participants' Web searching abilities (see Table 1). To preclude possible interfering effects of domain expertise, search tasks addressed a variety of topics. All searches were conducted using Internet Explorer 6 to access the Google search engine. Google was chosen because it is the predominant search engine among undergraduate students. Search outcomes were written down in an MsWord file. Computers were equipped with a registration program that captured the action from screen and saved it in an AVI movie file.

Insert Table 1 about here

\section{Procedure}

Pairs and Singles participated in the experiment one at a time, receiving the same instructions and following the same experimental procedures. All sessions took place in a quiet room equipped with one computer. One week prior to attending their session, students completed the background and MSLQ questionnaires. At the beginning of a session the experimenter introduced participants to the experimental procedures. Participants were then given the first search task, using a counterbalanced administration to anticipate order effects. Participants were allowed 15 minutes maximum to complete this task. If participants completed the task ahead of time, they called the experimenter to receive the second task. If participants exceeded the time limit, the experimenter interrupted task performance and handed out the second task. The other search tasks were administered similarly. Participants were not allowed to return to a previous task during the experiment. 


\section{Design and analyses}

The study used a between-subjects design with collaboration (Pair, Single) as the independent variable and search outcomes and regulation of search performance as dependent variables. Search outcomes was indicated by performance success and time. Performance success was the number of successfully completed search tasks; time was defined as the mean time for completed tasks.

Three measures were taken to assess regulation of search performance. These measures concerned planning, monitoring and evaluation, and were computed for completed tasks only. Planning was indicated by the number of times a new search strategy was adopted or an existing strategy was modified. Changing from entering a URL to a keyword search would be an example of adopting a new strategy. When keywords were changed or added but the strategy itself remained intact, this was scored as strategy modification. Monitoring was scored as (1) the proportion of relevant Web sites accessed through the search engine's hit list, (2) the proportion of correct initial answers derived from the target site, and (3) the proportion of incorrect initial answers taken from the target site. Evaluation was defined by (1) the proportion of initial answers that were checked, and (2) the number of times an initially incorrect answer was modified. Checking concerned returning to the same Web page to verify the answer; modifying involved making adjustments to the initial answer based on a culmination of searches.

Given the small sample size, Kolmogorov-Smirnov tests were performed to test the normality assumption. Levene's tests were used to check the homogeneity of variances among cell groups for all dependent variables. In case of homogeneity, univariate ANOVA's were used to examine the effect of collaboration on that variable. Variables with unequal variances were analyzed by means of $t$ tests with separate variance estimates. Pearson correlations were computed to examine the relationship between search outcomes and search performance.

\section{Results}

Preliminary analyses were performed to determine whether Pairs and Singles were comparable in terms of computer experience, Web searching experience, and self-regulation. The majority of the 
participants (54\%) spent more than 10 hours per week working with computers and searching the Web. The least experienced students used computers and the Internet for 2 to 5 hours per week. Chi square tests indicated that participants with varying levels of computer experience $\left(\chi^{2}(2)=0.11\right.$, $p=0.95)$ and Web searching experience $\left(\chi^{2}(2)=0.37, p=0.83\right)$ were proportionally distributed over experimental conditions. Likewise, no differences were observed between Pairs and Singles concerning their level of self-regulation (see Table 2)

Insert Table 2 about here

Table 3 summarizes the statistics for search outcomes. Pairs produced significantly higher performance success scores, indicating that they successfully completed more tasks than Singles did. Pairs also needed significantly less time to complete a task.

Insert Table 3 about here

Search performance was studied to examine the presence of self-regulatory activities in Pairs and Singles' search behavior. As shown in Table 4, Pairs demonstrated a richer repertoire of search strategies, starting a new approach more than once per task. For singles, this measure was significantly lower. No differences were found with regard to the number of modifications, indicating that Pairs and Singles just as often adapted an existing strategy.

In regards to monitoring, Pairs and Singles were equally proficient in judging the relevance of Websites from the search engines hit list. There is however reason to believe that Pairs were better at judging information within sites. When on the target site, Pairs tended to locate the target information more often than Singles did. Furthermore, Singles showed significantly higher proportions of incorrect initial answers: on $22.6 \%$ of the occasions they derived an incorrect initial answer from the target site.

Scores for evaluation also differed in favor of the Pairs. They checked their initial answer more often than Singles did, and almost twice as often tried to correct initially erroneous answers. Yet 
neither difference was supported by standard measures of statistical significance, which is probably due to the high variability of scores.

Insert Table 4 about here

Table 5 shows the relationships between search performance and search outcomes. The mean time to complete search tasks was relatively independent of measures indicating regulation of search performance. There was however a significant negative correlation between time and the proportion of initially correct answers, indicating that participants with higher proportions of initially correct answers also needed less time to complete the search tasks. The proportion initially (in)correct answers was also associated with performance success, and so were the proportions of checks and corrections. Successful Pairs and Singles apparently had more initially correct answers, checked their answers more often, and more often revised their answers.

Insert Table 5 about here

\section{Discussion}

This study examined the influence of collaboration on Web search behavior and search outcomes. Pairs of students were expected to achieve superior search outcomes and their search behavior was assumed to show higher proportions of self-regulatory activities.

The first hypothesis is clearly supported by the results. Pairs scored higher than Singles on measures that relate to search outcomes. They were faster and produced a greater number of correct responses to the tasks. These findings imply that Pairs search more efficiently: they need less time to successfully complete a task.

The results largely confirm the second hypothesis that collaboration would affect the regulation of search behavior. Pairs exhibited a richer repertoire of search strategies and were more proficient in monitoring and evaluating their search behavior. Superior monitoring arose because Pairs 
tended to be more proficient in locating the target information when it appeared on screen.

Conversely, Singles overlooked this information approximately $25 \%$ of the time, retrieving irrelevant or partially irrelevant information from the target site instead. The results for evaluation also differed in favor of the Pairs. They crosschecked initial answers more frequently and modified initially incorrect responses more than twice as often. Although the latter findings are not supported by standard measures of statistical significance, the direction of effect is supportive.

The observed differences in search outcomes can in part be explained by use of self-regulatory skills. Correlational analyses revealed that higher success rates are associated with higher degrees of monitoring and evaluating, and the occurrence rate of these activities differed in favor of the Pairs. These correlations further imply that checks, and particularly corrections, have converted initially incorrect answers into correct ones. Post hoc analyses support this contention: Pairs successfully corrected 7 out of 19 initially erroneous answers, versus 2 out of 19 for Singles. Performance time and regulation of search performance were unrelated, except for a significant negative correlation with initially correct answers. Fast-performing students apparently locate the target information more quickly, which is another indication that Pairs search more efficiently than Singles. It also proves that performing self-regulatory skills does not necessarily increase the time on task.

These correlations may nevertheless give a somewhat skewed reflection of the relationship between self-regulation and search outcomes. Checks and corrections can easily overshadow the effects of other regulatory activities because they have an immediate effect on search outcomes. The effects of conscious planning and careful monitoring can be wiped out in one fell swoop if students change an initially correct answer to an incorrect one. Post hoc analyses substantiate this. Stepwise multiple regression analysis revealed that the number of corrections accounts for $34 \%$ of the variance in search outcomes. However, in forced entry multiple regression none of the self-regulatory activities contribute to the variation in search outcomes.

These findings point out various directions for further research. First and foremost, this study should be replicated. As its sample was relatively small, research using a larger, and therefore more representative sample, is called for. These attempts might reveal additional benefits of collaboration: 
small sample size research is sensitive to type II errors, which means that there is a chance that true effects do not show in statistical analyses.

Future research might also seek to deepen our understanding of the relation between collaboration and self-regulation. One suggestion would be to examine qualitative differences in selfregulation. The scores presented here show that Pairs outperform Singles. They also indicate which regulatory activities account for these differences, but provide little insight into how exactly they were put into practice. In-depth analyses might uncover how collaboration adds to the quality of selfregulation and whether qualitative differences affect task outcomes.

It might be interesting from a didactical perspective to examine whether collaboration promotes the development of self-regulatory skills. Although self-regulatory skills can be taught through direct instruction, this approach seems inappropriate for technology-enhanced learning environments (Lazonder, 2003). Implementing self-regulatory skills instruction through collaboration could be a fruitful alternative since the presence of a fellow student provides a natural incentive to self-regulate. Future studies should also examine whether gains derived by collaboration carry over to individual performance. At some point students will presumably have to perform a task as individuals. The instructional efficacy of collaboration thus hinges on the transferability of collaboratively acquired self-regulatory skills to individual task performance.

While the exploratory nature of this study (and its sample size) does not allow for definitive conclusions on the benefits of collaborative Web searching, the results suggest that undergraduate students should work together when searching for information on the Web. As the effects of collaboration generalize across age groups, it is probably fair to conclude that high school students too can benefit from collaborative search efforts. This conclusion fits with the way the Web, or computers in general are being used in many classrooms. Practical constraints such as the availability of computers often leave teachers little choice but to embrace collaborative learning methods. This study suggests that these teachers have made a virtue of necessity. 


\section{Acknowledgements}

This study used the dataset of an unpublished study by Amber Walraven and Bastiaan van Rootselaar, whose permission to re-analyze their data files and screen recordings is gratefully acknowledged. Special thanks to Hans van der Meij and Sarah Manlove for helpful comments provided during the preparation of this paper. 


\section{References}

Branch J L (2001) Junior high students and thinks alouds: generating information-seeking process data using concurrent verbal protocols Library \& Information Science Research 23, 107-122.

Caskey M M (2003) Using parent-student pairs for internet instruction Journal of Research on Technology in Education 34, 304-318.

Chau M, Zeng D, Chen H, Huang M and Hendriawan D (2003) Design and development of a multiagent collaborative Web mining system Decision Support Systems 35, 167-183.

Cohen E (1994) Restructuring the classroom: conditions for productive small groups Review of Educational Research, 64, 1-35.

Colaric S M (2003) Instruction for Web searching: an empirical study College \& Research Libraries 64, 111-122.

Druin A, Revelle G, Bederson B B, Hourcade J P, Farber A, Lee J and Campbell D (2003) A collaborative digital library for children Journal of Computer Assisted Learning 19, 239-248.

Fleming V M and Alexander J M (2001) The benefits of peer collaboration: a replication with a delayed posttest Contemporary Educational Psychology 26, 588-601.

Large A, Beheshti J and Rahman T (2002) Gender differences in collaborative Web searching behavior: an elementary school study Information Processing and Management 38, 427-443.

Lazonder A W (2000) Exploring novice users' training needs in searching information on the World Wide Web Journal of Computer Assisted Learning 16, 326-335.

Lazonder A W (2001) Minimalist instruction for learning to search the World Wide Web Education and Information Technologies 6, 161-176.

Lazonder A W (2003) Principles for designing Web searching instruction Education and Information Technologies 8, 179-193.

Lou Y, Abrami P C, Spence J C and 'd Apollonia S (2001) Small group and individual learning with technology: a meta analysis Review of Educational Research 71, 449-521.

Pelgrum W J (1999) Curriculum and pedagogy in Pelgrum W J and Anderson R E (eds) ICT and the emerging paradigm for lifelong learning IEA, Amsterdam, 89-119. 
Pintrich P R, Smith D A F, Garcia T and McKeachie W J (1993) Reliability and predictive validity of the Motivated Strategies for Learning Questionnaire (MSLQ) Educational and Psychological Measurement 53, 801-813.

Prekop P (2002) A qualitative study of collaborative information seeking Journal of Documentation $58,533-547$.

Schauble L, Klopfer L and Raghavan K (1991) Students' transitions from an engineering to a science model of experimentation. Journal of Research in Science Teaching 28, 859-882.

Schraw G (1994) The effects of metacognitive knowledge on local and global monitoring Contemporary Educational Psychology 19, 143-154.

Taylor R S (1968) Question-negotiation and information seeking in libraries College \& Research Libraries 29, 178-195.

Teasley S D (1995) The role of talk in children's peer collaborations Developmental Psychology 31, $207-220$.

Ten Brummelhuis A C A and Slotman K M J (2000) ICT monitor 1998/1999: Voortgezet onderwijs [ICT monitor 1998/1999: Secundary education]. University of Twente, The Netherlands.

Twidale M and Nichols D (1998) Designing interfaces to support collaboration in information retrieval Interacting with Computers 10, 177-193.

Veenman M V J, Elshout J J and Meijer J (1997) The generality vs domain-specificity of metacognitive skills in novice learning across domains Learning and Instruction 7, 187-209.

Zimbardo P G, Butler L D and Wolfe V A (2003) Cooperative college examinations: more gain, less pain when student share information and grades The Journal of Experimental Education 71, $101-125$. 
1. When was the first version of MS Windows released?

2. What extinct species is found in Alice in Wonderland?

3. There have been quite some attempts to circle the earth by hot air balloon. How many tries were needed to become the first man to achieve solo circumnavigation of the earth in a hot air balloon?

4. For what reasons was the European Union established?

5. Most people know that indians live in tents. Inside and outside these tents certain traditions and rules should be complied with. To illustrate, indians don't want 'direct' help in taking down their tent. Why is that so?

6. Find the current opinions of three major European countries on a possible war with Iraq. 
Table 2: Mean scores (and standard deviations) for level of self-regulation

\begin{tabular}{|c|c|c|c|c|}
\hline & \multicolumn{2}{|c|}{ Condition } & \multirow[b]{2}{*}{$F(1,22)$} & \multirow[b]{2}{*}{ MSE } \\
\hline & Single & Pair & & \\
\hline Self-efficacy & $5.5(0.6)$ & $4.9(0.9)$ & 2.24 & 0.76 \\
\hline Task value & $6.1(0.9)$ & $5.7(1.4)$ & 0.68 & 1.58 \\
\hline Test anxiety & $2.2(1.0)$ & $2.8(1.1)$ & 1.31 & 1.21 \\
\hline Cognitive strategies & $4.2(1.2)$ & $4.3(0.5)$ & $0.40^{\mathrm{a}}$ & 0.48 \\
\hline Metacognitive strategies & $5.5(0.8)$ & $5.0(0.7)$ & 1.90 & 0.54 \\
\hline
\end{tabular}

Note. Analyses compared scores of individual participants from both conditions $(n=25)$

${ }^{\mathrm{a}} \mathrm{t}$-test with separate variance estimate 
Table 3: Mean scores (and standard deviations) for search outcomes

\begin{tabular}{|c|c|c|c|c|}
\hline & \multicolumn{2}{|c|}{ Condition } & \multirow[b]{2}{*}{$F(1,14)$} & \multirow[b]{2}{*}{ MSE } \\
\hline & Single & Pair & & \\
\hline Success & $2.0(1.0)$ & $3.6(1.0)$ & $9.38 * *$ & 1.02 \\
\hline Time (min.) & $6.4(1.7)$ & $4.3(2.1)$ & $4.78^{*}$ & 3.66 \\
\hline
\end{tabular}


Table 4: Mean scores (and standard deviations) for regulation of search performance

\begin{tabular}{|c|c|c|c|c|c|}
\hline & & \multicolumn{2}{|c|}{ Condition } & \multirow[b]{2}{*}{$F(1,14)$} & \multirow[b]{2}{*}{ MSE } \\
\hline & & Single & Pair & & \\
\hline \multirow[t]{2}{*}{ Planning } & No. of new strategies & $0.2(0.4)$ & $1.2(0.6)$ & $14.28 * *$ & 0.26 \\
\hline & No. of modifications & $2.1(2.6)$ & $1.4(0.8)$ & 0.53 & 3.28 \\
\hline \multirow[t]{3}{*}{ Monitoring } & $\%$ relevant sites & $90.2(12.4)$ & $84.3(12.4)$ & 0.90 & 154.15 \\
\hline & $\%$ correct initial answers $^{1}$ & $41.2(16.6)$ & $59.8(21.9)$ & $3.48^{*}$ & 392.52 \\
\hline & $\%$ incorrect initial answers ${ }^{1}$ & $22.6(12.6)$ & $1.9(5.6)$ & $19.78 * *$ & 85.83 \\
\hline \multirow[t]{2}{*}{ Evaluation } & $\%$ checks & $27.1(23.6)$ & $35.0(23.6)$ & 0.44 & 557.04 \\
\hline & No. of corrections & $1.4(1.5)$ & $3.9(4.9)$ & 1.67 & 14.94 \\
\hline
\end{tabular}

\footnotetext{
${ }^{1}$ These scores do not add up to $100 \%$ because participants could also derive an incorrect answer from an incorrect site

$* p<.10 * * p<.01$
} 
Collaborative Web searching

Table 5: Correlations between search outcomes and regulation of search performance

\begin{tabular}{llll}
\hline \multirow{2}{*}{ Search performance } & \multicolumn{2}{c}{ Search outcomes } \\
\cline { 3 - 4 } & & Success & Time \\
\hline Planning & No. of new strategies & 0.27 & -0.06 \\
& No. of modifications & -0.18 & 0.16 \\
Monitoring & $\%$ relevant sites & -0.21 & 0.13 \\
& $\%$ correct initial answers & $0.38^{*}$ & $-0.43^{* *}$ \\
& $\%$ incorrect initial answers & $-0.34^{*}$ & 0.26 \\
Evaluation & $\%$ checks & $0.48^{* *}$ & 0.02 \\
& No. of corrections & $0.62^{* * *}$ & -0.17 \\
\hline$* p<.10 * * p<.05 * * * p<.01$ & &
\end{tabular}

